\title{
Pemanfaatan Kolam Ikan Untuk Budidaya Tanaman Dengan Aquaponik
}

\author{
Sapto Wibowo*1 \\ 1Program Studi Agroindustri, Politeknik Banjarnegara \\ *e-mail: sapto_wbw@yahoo.com ${ }^{1}$
}

\begin{abstract}
Fish ponds, apart from being used for fish farming, can also be used for plant cultivation using a method called aquaponics. Most of the people of Pucang Village do not know about aquaponics, so the fish pond in the yard of the house has not been used for plant cultivation. This activity aims to ensure that members of the Sida Makmur Village Women Farmers Group (KWT) have knowledge of the use of fish ponds for aquaponics cultivation, and are motivated to utilize fish ponds for plant cultivation in order to meet family food and nutritional needs. The method given in this activity is counseling on the use of fish ponds for aquaponic plant cultivation, followed by discussions and demonstrations of the manufacture and transfer of plants to an aquaponic system. After this PKM activity was completed, it was known that the members of KWT Sida Makmur Pucang Village were very enthusiastic about participating in aquaponics counseling activities, their knowledge of aquaponics increased, and most members were motivated to use fish ponds for aquaponics cultivation.
\end{abstract}

Keywords: Aquaponics, Fish pond, Plant cultivation

\begin{abstract}
Abstrak
Kolam ikan, selain dapat digunakan untuk budidaya ikan, juga dapat digunakan untuk budidaya tanaman dengan metode yang disebut aquaponik. Sebagian besar masyarakat Desa Pucang belum mengetahui tentang aquaponik, sehingga kolam ikan yang ada di pekarangan rumah belum termanfaatkan untuk budidaya tanaman. kegiatan ini bertujuan agar anggota Kelompok Wanita Tani (KWT) Sida Makmur Desa Pucang memiliki pengetahuan tentang pemanfaatan kolam ikan untuk budidaya tanaman secara aquaponik, serta termotivasi untuk memanfaatkan kolam ikan untuk budidaya tanaman dalam rangka memenuhi kebutuhan pangan dan gizi keluarga. Metode yang diberikan dalam kegiatan ini adalah penyuluhan pemanfaatan kolam ikan untuk budidaya tanaman secara aquaponik, dilanjutkan dengan diskusi dan demonstrasi pembuatan dan pemindahan tanaman ke sistem aquaponik. Setelah kegiatan PKM ini selesai dilaksanakan diketahui bahwa anggota KWT Sida Makmur Desa Pucang sangat antusias untuk mengikuti kegiatan penyuluhan aquaponik, pengetahuan tentang aquaponik meningkat, dan sebagian besar anggota termotivasi untuk memanfaatkan kolam ikan untuk budidaya tanaman dengan aquaponik.
\end{abstract}

Kata kunci: Aquaponik, Budidaya tanaman, Kolam ikan

\section{PENDAHULUAN}

"Kolam ikan merupakan tempat penampungan air dengan berbagai bentuk dan sebutan, yang dapat dimanfaatkan untuk berbagai kegiatan, baik itu untuk hobi, penghasilan, atau keindahan, misalnya tempat pemancingan, kolam budidaya ikan, dan kolam sebagai hiasan di pekarangan rumah. Pada tempat-tempat tertentu biasanya kolam ikan digunakan sebagai mata pencaharian dalam memenuhi kehidupan. FAO merekomendasikan kolam budidaya ikan sebagai sumber penghasilan, untuk memenuhi kebutuhan pangan, sumber air pertanian dan peternakan agar dikembangkan di negara miskin dan berkembang" (Wikipedia, 2021).

"Aquaponik adalah sistem pertanian berkelanjutan yang sudah lama berkembang di Indonesia, dan merupakan jenis urban farming yang sedang tren, yang menggabungkan antara hidroponik dengan akuakultur dalam suatu hubungan yang sifatnya simbiotik. Simbiotik berarti bahwa tanaman memanfaatkan ekskresi dari ikan sebagai sumber nutrisi yang diproses secara alami dari nitrit menjadi nitrat. Dalam sistem aquaponik, air tersirkulasi dengan menggunakan pompa. Air yang mengandung kotoran ikan dari kolam dialirkan menuju ke tanaman yang memanfaatkannya sebagai sumber nutrisi dan selanjutnya air yang sudah tersaring akan dikembalikan menuju ke kolam. Sistem aquaponik ini sangat beragam bentuknya, baik dari segi 
ukuran, maupun jenis tanaman dan ikan yang dibudidayakan" (Zulhelman et al., 2016). Sedang Gumelar et al. (2017) menyatakan bahwa "Kombinasi antara budidaya ikan dan budidaya tanaman di mana unsur hara tanaman diperoleh dari bahan organik yang ada dalam kolam ikan disebut sebagai aquaponik".

Beberapa metode hidroponik telah dikembangkan pada saat ini, salah satunya adalah hidroponik DFT (Deep Flow Technique). Hidroponik DFT merupakan sistem hidroponik dengan meletakkan akar tanaman pada lapisan nutrisi. Sesanti \& Sismanto (2016) menyatakan bahwa "Ketinggian lapisan nutrisi pada sistem DFT adalah 3-4 cm". Sedang Wibowo (2020) menyatakan bahwa "Hidroponik DFT model anak tangga, model meja, dan model piramida merupakan beberapa model hidroponik yang telah dikembangkan. Model-model tersebut mempunyai nilai estetika dan indah untuk dipandang sehingga disukai oleh masyarakat. Dari segi bentuknya, ketiga model tersebut memiliki perbedaan. Model anak tangga bentuknya bertingkat lima menyerupai anak tangga atau bangku, model meja bentuknya datar menyerupai meja, dan model piramida bentuknya persegi bertingkat tiga dengan ukuran semakin ke atas semakin kecil".

Desa Pucang merupakan salah satu desa yang terletak di Kecamatan Bawang Kabupaten Banjarnegara. Beberapa warga memiliki lahan pekarangan yang dimanfaatkan sebagai kolam ikan untuk budidaya ikan lele, nila, atau gurami. Dengan adanya kolam ikan tersebut sudah membantu masyarakat untuk memenuhi kebutuhan pangan dan gizi keluarga, bahkan ada yang bisa menambah pendapatan ekonomi. Pada masa pandemi covid-19 ini, pemerintah menganjurkan agar masyarakat agar lebih meningkatkan ketahanan pangan dan gizi rumah tangga dengan cara melakukan kegiatan dari rumah. Ekawati et al. (2020) menyatakan bahwa "Pemanfaatan lahan pekarangan rumah secara optimal dapat dilakukan dengan cara menanam tanaman obat-obatan, tanaman hias, dan tanaman pangan yang dapat menghasilkan nilai ekonomi tinggi sebagai upaya memenuhi kebutuhan pangan dalam kondisi lahan pertanian yang sempit".

"Kaum perempuan diberikan kesempatan untuk berperan aktif dalam memajukan sector pertanian dalam suatu wadah yang disebut Kelompok Wanita Tani (KWT). Penggunaan KWT adalah sebagai sarana untuk memberdayakan petani wanita dalam meningkatkan mutunya, dengan mengikuti kegiatan-kegiatan dalam aktualisasinya" (Purnamasari, 2014). KWT Sida Makmur Desa Pucang Kabupaten Banjarnegara merupakan organisasi yang beranggotakan ibuibu lingkungan sekitar, dengan tujuan dapat memberikan kesempatan bagi perempuan di desa tersebut untuk menyalurkan kemampuannya dalam mengolah lahan pertanian maupun pekarangan rumah, melalui berbagai kegiatan yang diadakan oleh KWT sehingga dapat meningkatkan aktualisasi mereka di lingkungan sosialnya.

Dari hasil diskusi diketahui bahwa sebagian besar masyarakat Desa Pucang belum mengetahui tentang aquaponik, sehingga kolam ikan yang ada di pekarangan rumah belum termanfaatkan untuk budidaya tanaman. Oleh karena itu, untuk menambah pengetahuan dan manfaat kolam ikan untuk budidaya tanaman maka perlu adanya pelatihan tentang aquaponik dengan hidroponik DFT terhadap KWT Sida Makmur Desa Pucang.

Pengabdian kepada masyarakat ini bertujuan memberikan bekal pengetahuan dan ketrampilan kepada anggota KWT Sida Makmur Desa Pucang tentang aquaponik, serta memberikan motivasi untuk memanfaatkan lahan pekarangan rumah sebagai sumber pangan keluarga dan pemenuhan gizi keluarga di masa pandemi covid-19.

\section{METODE}

Waktu dan Tempat

Kegiatan pengabdian kepada masyarakat (PKM) ini dilaksanakan bulan Juli 2020 di Desa Pucang Kecamatan Bawang Kabupaten Banjarnegara. Metode yang diberikan dalam kegiatan ini adalah penyuluhan pemanfaatan kolam ikan untuk budidaya tanaman secara aquaponik yang dilanjutkan dengan diskusi, dan demonstrasi pembuatan dan pemindahan tanaman ke sistem 
aquaponik. Khalayak sasaran kegiatan PKM ini adalah Kelompok Wanita Tani (KWT) Sida Makmur Desa Pucang yang berjumlah 20 orang.

\section{Alat dan Bahan}

Alat yang digunakan pada kegiatan ini adalah kolam ikan, Hidroponik DFT (Deep Flow Technique), ember, soldir, gelas plastik bekas yang dilubangi pada bagian bawah dan samping sebagai net pot, dan tray semai. Sedangkan bahan yang digunakan adalah benih tanaman selada, rockwool, dan arang sekam.

\section{Tahapan Kegiatan}

1. Penyuluhan dan diskusi tentang pemanfaatan kolam ikan untuk budidaya tanaman secara aquaponik dengan hidroponik DFT.

2. Dilanjutkan dengan demonstrasi, mulai dari persemaian sampai dengan pembuatan dan pemindahan tanaman ke sistem aquaponik, dengan langkah-langkah:

a. Rockwool dipotong-potong kecil untuk media semai benih, selanjutnya dibasahi dan dimasukkan ke dalam tray semai.

b. Benih diletakkan satu-satu di atas rockwool dalam tray semai, dan setelah umur semai \pm 2 minggu atau tumbuh 3-4 helai daun tanaman,

c. Benih yang telah menjadi bibit siap dipindah ke gelas plastik berlubang (sebagai net pot) yang sudah diisi arang sekam basah.

d. Hidroponik DFT diinstal sehingga siap digunakan.

e. Gelas plastik dengan tanaman diletakkan pada lubang-lubang di alat hidroponik.

f. Pompa dihidupkan sehingga air dari kolam ikan mengalir ke alat hidroponik, dan kembali lagi ke kolam ikan.

g. Untuk menghemat listrik maka pada sore hari pompa dimatikan dan dihidupkan lagi pada pagi hari.

3. Test kemampuan dengan membagikan kuesioner sebelum dan sesudah kegiatan dilaksanakan.

\section{HASIL DAN PEMBAHASAN}

Penyuluhan dan Diskusi

Kegiatan pengabdian kepada masyarakat (PKM) ini dilaksanakan pada bulan Juli 2020 di RW 09 Desa Pucang Kecamatan Bawang Kabupaten Banjarnegara, dan dihadiri oleh para anggota KWT Sida Makmur Desa Pucang yang berjumlah 20 orang.

Menurut Wiguna (sebagaimana dikutip dalam Maharani \& Sari, 2016) bahwa "Aquaponik merupakan salah satu alternatif yang dapat diterapkan sebagai solusi yang bermanfaat dalam pengolahan limbah cair kolam ikan. Aquaponik merupakan gabungan antara budidaya ikan dengan budidaya tanaman secara hidroponik. Limbah cair ikan dalam kolam akan dialirkan secara sirkulasi dalam sistem aquaponik menuju media tanam hidroponik yang akan diserap dan dimanfaatkan sebagai nutrisi tanaman". Rahma (sebagaimana dikutip dalam Maharani \& Sari, 2016) menyatakan bahwa "Fungsi dari tanaman adalah sebagai biofilter yang akan menyerap zatzat yang berbahaya bagi ikan, seperti fosfor, nitrit, nitrat, dan amonia". Sedang Endut et al. (sebagaimana dikutip dalam Rini et al., 2018) menyatakan bahwa "Sistem resirkulasi akuakultur yaitu hidroponik dengan media air dengan bentuk khusus, dengan air tersirkulasi yang dibuat dengan budidaya ikan disebut sebagai aquaponik. Aquaponik bertujuan untuk memanfaatkan nutrien bagi tanaman yang berasal dari ikan agar tidak mengganggu perkembangan ikan dengan menggunakan biofilter dari bagian hidroponik". Sagita et al. (sebagaimana dikutip dalam Wicaksana et al., 2015) menyatakan bahwa "Biofilter aquaponik adalah suatu sistem di mana mutu air dipertahankan di atas ambang yang diperbolehkan selama kurun waktu tertentu pada 
teknik budidaya dengan perkembangan ikan tidak terganggu yang digabungkan dengan budidaya tanaman".

Materi penyuluhan dan diskusi yang disampaikan adalah tentang pemanfaatan kolam ikan untuk budidaya tanaman secara aquaponik dengan hidroponik DFT. Peserta yang hadir dalam kegiatan PKM ini sangat antusias mengikuti acara penyuluhan, terlihat dari respon yang diberikan oleh peserta melalui banyaknya pertanyaan-pertanyaan yang diajukan oleh peserta. Mereka sangat tertarik mendengarkan penjelasan dari narasumber serta berdiskusi tentang pemanfaatan kolam ikan selain untuk budidaya ikan, tentang hidroponik DFT, dan tentang aquaponik (Gambar 1).

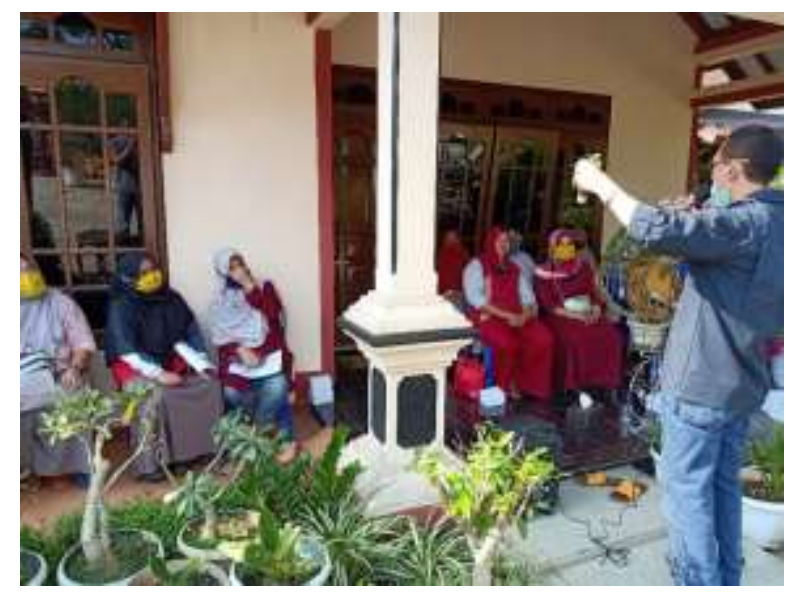

Gambar 1. Kegiatan penyuluhan dan diskusi

\section{Demonstrasi}

Demonstrasi merupakan suatu metode penyajian penyuluhan atau pelatihan secara langsung, dengan cara memeragakan suatu proses kegiatan menggunakan alat-alat bantu untuk menunjang kegiatan tersebut. Dalam kegiatan PKM ini, demonstrasi diajarkan mulai dari persemaian sampai pemindahan bibit tanaman ke sistem aquaponik. Para anggota KWT Sida Makmur Pucang sangat antusias mengikuti demonstrasi dengan cara mempraktekkan secara langsung. Dengan demikian, selain ilmu pengetahuan yang diperoleh, para anggota KWT Sida Makmur Desa Pucang juga memiliki keterampilan dalam memanfaatkan kolam ikan untuk budidaya tanaman dengan sistem aquaponik. Kegiatan demonstrasi saat kegiatan PKM disajikan pada Gambar 2, 3, dan 4.

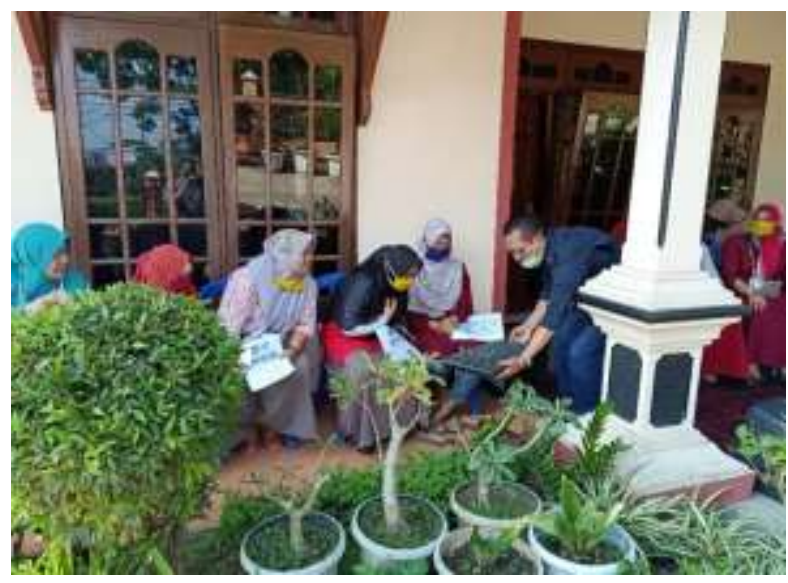

Gambar 2. Semai benih dengan rockwool 


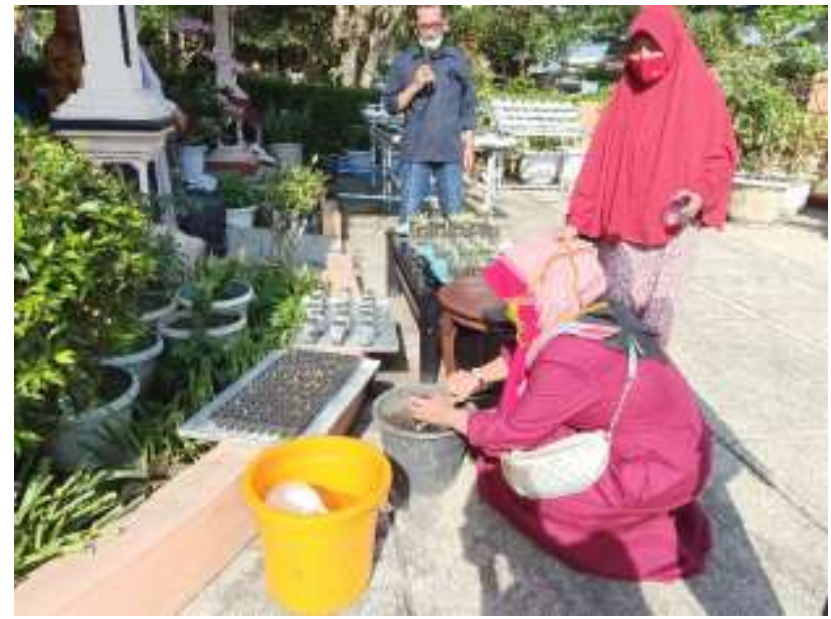

Gambar 3. Pemindahan bibit ke gelas plastik berlubang yang sudah diisi arang sekam basah

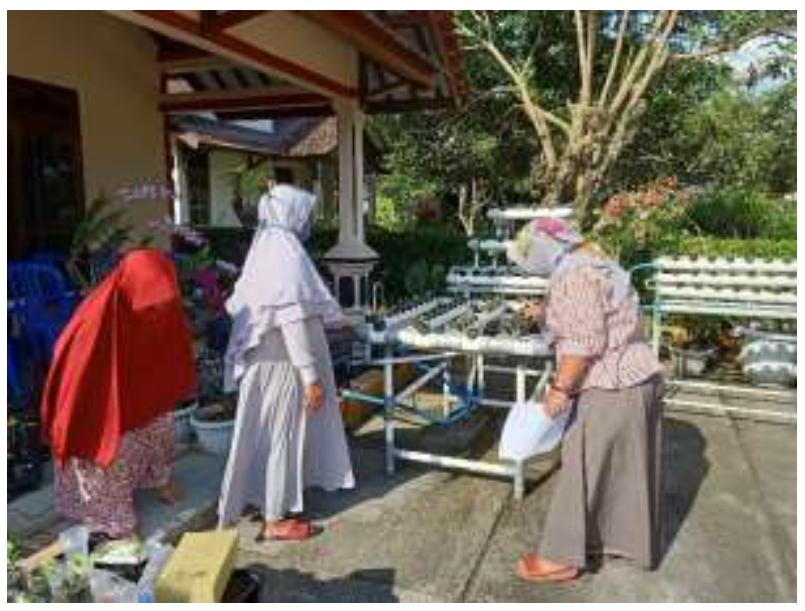

Gambar 4. Pemindahan bibit pada sistem aquaponik dengan hidroponik DFT

\section{Hasil Test Kemampuan}

Dalam melaksanakan kegiatan PKM ini, dibuat suatu instrumen pengukuran berupa kuesioner yang harus diisi sebelum dan sesudah kegiatan dilaksanakan. Kuesioner yang dibagikan berisi pertanyaan mulai dari tingkat pengetahuan tentang pengertian aquaponik sampai dengan motivasi memanfaatkan kolam ikan dengan aquaponik. Hasil test kemampuan sebelum dan sesudah kegiatan pelatihan aquaponik dilaksanakan disajikan pada Tabel 1.

Tabel 1. Hasil test kemampuan sebelum dan sesudah kegiatan dilaksanakan

No. Sebelum kegiatan Sesudah kegiatan

1 Tingkat pengetahuan tentang pengertian aquaponik masih rendah (semua peserta tidak tahu $=0 \%$ )

$2 \quad$ Tingkat pengetahuan tentang aplikasi aquaponik masih rendah (semua peserta belum pernah melihat $=0 \%$ )

3 Tingkat pengetahuan tentang pupuk yang digunakan dalam aquaponik masih rendah (semua peserta tidak tahu $=0 \%$ )
Tingkat pengetahuan tentang pengertian aquaponik meningkat (semua peserta tahu $=100 \%$ )

Tingkat pengetahuan tentang aplikasi aquaponik meningkat (semua peserta melihat secara langsung $=100 \%$ )

Tingkat pengetahuan tentang pupuk yang digunakan dalam aquaponik meningkat $(16 / 20=80 \%$ peserta tahu $)$ 


\begin{tabular}{lll}
4 & $\begin{array}{l}\text { Tingkat pengetahuan tentang } \\
\text { hidroponik DFT masih rendah (semua } \\
\text { peserta tidak tahu }=0 \%)\end{array}$ & $\begin{array}{l}\text { Tingkat pengetahuan tentang hidroponik } \\
\text { DFT meningkat }(14 / 20 \text { peserta }=70 \% \\
\text { peserta tahu) }\end{array}$ \\
5 & $\begin{array}{l}\text { Pemanfaatan kolam ikan dengan } \\
\text { aquaponik masih rendah (semua } \\
\text { peserta belum memanfaatkan }=0 \%)\end{array}$ & $\begin{array}{l}\text { Motivasi memanfaatkan kolam ikan } \\
\text { dengan aquaponik meningkat }(14 / 20 \\
\text { peserta }=70 \% \text { peserta berkeinginan } \\
\text { untuk memanfaatkan kolam ikan dengan } \\
\text { aquaponik) }\end{array}$ \\
\hline
\end{tabular}

Hasil pengukuran yang disajikan pada Tabel 1 menggambarkan bahwa peserta pada umumnya tidak mengetahui tentang pengertian aquaponik, dan tidak mengetahui bahwa kolam ikan dapat digunakan untuk budidaya tanaman dengan aquaponik, serta belum pernah melihat aplikasi aquaponik. Para peserta menganggap bahwa aquaponik adalah sesuatu yang asing, belum pernah dilihat dan sulit untuk dilaksanakan. Para peserta juga belum mengetahui bahwa budidaya tanaman dengan aquaponik tidak membutuhkan pupuk/larutan nutrisi karena dapat dilakukan dengan memanfaatkan air kolam yang mengandung unsur nitrat yang berasal dari kotoran maupun sisa makanan ikan. Selain itu, para peserta juga belum mengetahui tentang hidroponik DFT.

Setelah kegiatan dilaksanakan terjadi peningkatan terhadap pengetahuan tentang pengertian aquaponik, tentang hidroponik DFT, dan tentang pemanfaatan kolam ikan untuk budidaya tanaman dengan aquaponik. Para anggota KWT Sida Makmur Desa Pucang yang sebelum kegiatan belum memanfaatkan kolam ikan dengan aquaponik, setelah kegiatan sebagian besar anggota menjadi termovitasi untuk memanfaatkan kolam ikan untuk budidaya tanaman dengan aquaponik. Dengan demikian, kebutuhan gizi pangan keluarga yang berupa ikan dan sayuran akan tercukupi.

\section{KESIMPULAN}

a. Anggota KWT Sida Makmur Desa Pucang sangat antusias untuk mengikuti kegiatan penyuluhan tentang aquaponik.

b. Pengetahuan anggota KWT Sida Makmur Desa Pucang tentang aquaponik meningkat.

c. Sebagian besar anggota KWT Sida Makmur Desa Pucang anggota KWT termotivasi untuk memanfaatkan kolam ikan untuk budidaya tanaman dengan aquaponik.

d. Perlu pengembangan pelatihan pembuatan hidroponik DFT agar bisa diaplikasikan bersama sistem aquaponik.

\section{UCAPAN TERIMA KASIH}

Penulis mengucapkan terima kasih kepada anggota KWT Sida Makmur Desa Pucang yang telah bersedia meluangkan waktu dan mendukung kegiatan ini sehingga dapat terlaksana dengan baik dan lancar.

\section{DAFTAR PUSTAKA}

Ekawati, Rizieq, R., \& Kurniawan, H. M. (2020). Pemanfaatan Lahan Pekarangan dalam Mendukung Ketahanan Pangan Rumah Tangga Melalui Metode Vertikultur. Dinamisia, 4(3), 454-460. https://doi.org/https://doi.org/10.31849/dinamisia.v4i3.4133

Gumelar, W. R., Nurruhwati, I., Sunarto, \& Zahidah. (2017). Pengaruh Penggunaan Tiga Varietas Tanaman Pada Sistem Akuaponik Terhadap Konsentrasi Total Amonia Nitrogen Media Pemeliharaan Ikan Koi. Jurnal Perikanan Dan Kelautan, VIII(2), 36-42.

Maharani, N. A., \& Sari, P. N. (2016). Penerapan Aquaponic Sebagai Teknologi Tepat Guna 
Pengolahan Limbah Cair Kolam Ikan Di dusun Kergan, Tirtomulyo, Kretek, Bantul, Yogyakarta. Indonesian Journal of Ommunity Engagement, 1(2), 172-182.

Purnamasari, L. (2014). Pemberdayaan Perempuan Melalui Kelompok Wanita Tani (KWT) Bagi Aktualisasi Perempuan Di Desa Kemanukan, Bagelen, Purworejo, Jateng. Skripsi, 116.

Rini, D. S., Hasan, H., \& Prasetio, E. (2018). Sistem Akuaponik Dengan Jenis Tumbuhan Yang Berbeda Terhadap Pertumbuhan Benih Ikan Tengadak (Barbonymus scwanenfeldii). Jurnal Ruaya: Jurnal Penelitian Dan Kajian Ilmu Perikanan Dan Kelautan, 6(2), 14-20. https://doi.org/10.29406/rya.v6i02.1007

Sesanti, R. N., \& Sismanto. (2016). Pertumbuhan dan Hasil Pakchoi (Brasicca rapa L.) pada Dua Sistem Hidroponik dan Empat Jenis Nutrisi. Jurnal Kelitbangan, 04(01), 1-9.

Wibowo, S. (2020). Pengaruh Aplikasi Tiga Model Hidroponik DFT Terhadap Tanaman Pakcoy (Brassica rapa L.). Jurnal Keteknikan Pertanian Tropis Dan Biosistem, 8(3), 245-252. https://doi.org/10.21776/ub.jkptb.2020.008.03.06

Wicaksana, S. N., Hastuti, S., \& Arini, E. (2015). Performa Produksi Ikan Lele Dumbo (Clarias gariepinus) Yang Dipelihara Dengan Sistem Biofilter Akuaponik Dan Konvensional. Journal of Aquaculture Management and Technology, 4(4), 109-116.

Wikipedia. (2021). Kolam ikan. https://id.wikipedia.org/wiki/Kolam_ikan

Zulhelman, Ausha, H. A., \& Ulfa, R. M. (2016). Pengembangan Sistem Smart Aquaponik. Jurnal PoliTeknologi, 15(2), 181-186. 